\title{
Salmonella Meningitis Associated with Monocyte Infiltration in Mice
}

Timothy J. Bauler, ${ }^{*}$ Tregei Starr, ${ }^{*}$ Toni A. Nagy, ${ }^{\dagger}$ Sushmita Sridhar, ${ }^{*}$ Dana Scott, ${ }^{\ddagger}$ Clayton W. Winkler,${ }^{\S}$ Olivia Steele-Mortimer, ${ }^{*}$ Corrella S. Detweiler, ${ }^{\dagger}$ and Karin E. Peterson ${ }^{\S}$

From the Laboratories of Bacteriology* and Persistent Viral Diseases ${ }^{\S}$ and the Rocky Mountain Veterinary Branch, ${ }^{\ddagger}$ Rocky Mountain Laboratories, National Institute of Allergy and Infectious Diseases, National Institutes of Health, Hamilton, Montana; and the Department of Molecular, Cellular and Developmental Biology, ${ }^{\dagger}$ University of Colorado Boulder, Boulder, Colorado

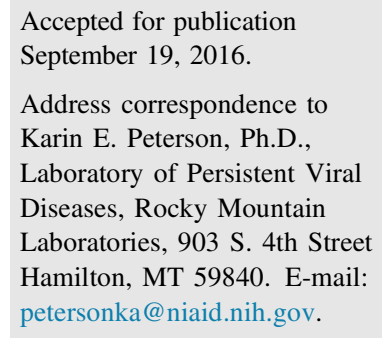

\begin{abstract}
In the current study, we examined the ability of Salmonella enterica serovar Typhimurium to infect the central nervous system and cause meningitis following the natural route of infection in mice. $\mathrm{C} 57 \mathrm{BL} / 6 \mathrm{~J}$ mice are extremely susceptible to systemic infection by Salmonella Typhimurium because of loss-of-function mutations in Nramp1 (SLC11A1), a phagosomal membrane protein that controls iron export from vacuoles and inhibits Salmonella growth in macrophages. Therefore, we assessed the ability of Salmonella to disseminate to the central nervous system (CNS) after oral infection in C57BL/6J mice expressing either wild-type (resistant) or mutant (susceptible) alleles of Nramp1. In both strains, oral infection resulted in focal meningitis and ventriculitis with recruitment of inflammatory monocytes to the CNS. In susceptible $\mathrm{Nramp1}^{-/-}$mice, there was a direct correlation between bacteremia and the number of bacteria in the brain, which was not observed in resistant $N$ ramp $1^{+/+}$mice. A small percentage of $N$ ramp $1^{+/+}$mice developed severe ataxia, which was associated with high bacterial loads in the CNS as well as clear histopathology of necrotizing vasculitis and hemorrhage in the brain. Thus, Nramp1 is not essential for Salmonella entry into the CNS or neuroinflammation, but may influence the mechanisms of CNS entry as well as the severity of meningitis. (Am J Pathol 2017, 187: 187-199; http://dx.doi.org/10.1016/j.ajpath.2016.09.002)
\end{abstract}

Meningitis caused by Salmonella enterica serovars is a lifethreatening disease with high fatality rates and frequent long-term neuropsychological sequelae. ${ }^{1}$ Although this is a rare disease in most parts of the world, in sub-Saharan Africa nontyphoidal S. enterica, particularly serovar Typhimurium (Salmonella Typhimurium), is now one of the most common causes of bacterial meningitis. ${ }^{2,3}$ In severe cases, Salmonella meningitis can lead to ventriculitis, hydrocephalus, or cerebral abscess. ${ }^{4-7}$

Animal models are essential to study of the mechanisms involved in bacterial meningitis, particularly entry into the central nervous system (CNS) and induction of meningeal inflammation. Recently, Salmonella Typhimurium was shown to be able to infect the CNS after oral inoculation in mice. ${ }^{8,9}$ In addition, a few animals developed clinical signs of rolling that may be indicative of Salmonella-induced neurological damage. ${ }^{9}$ These studies indicate that mice may be a useful model to study Salmonella meningitis after the natural oral route of infection. A natural route of infection would allow analysis of the relative rate of Salmonella infection in the CNS, the correlation of brain infection with peripheral infection, and the association of an inflammatory response with infection in the brain. Furthermore, a natural route model would allow for the analysis of how the peripheral host immune response influences the ability of Salmonella to gain access to the brain as well as the development of bacterial meningitis.

In mice, a significant component of innate resistance to Salmonella Typhimurium is because of the natural resistance-associated macrophage protein 1 (Nrampl; alias Slcl1al), a divalent cation transporter expressed in cells of

Supported in part by the National Institute of Allergy and Infectious Diseases Intramural Program and in part by NIH grant R01AI095395.

T.J.B., T.S., and T.A.N. contributed equally to this work.

Disclosures: None declared.

Current address of T.J.B., Department of Biomedical Sciences, Western Michigan University Homer Stryker M.D. School of Medicine, Kalamazoo, MI. 
the monocyte/macrophage lineage. NRAMP1 limits the amount of iron within phagosomes and thus restricts replication of vacuolar pathogens, such as Salmonella, within macrophages. ${ }^{10}$ During the early phase of infection, NRAMP1 restricts the intracellular replication of Salmonella in the reticuloendothelial organs. ${ }^{11}$ Murine strains with homozygous loss-of-function mutations in Nrampl (eg, $\mathrm{BALB} / \mathrm{c}$ and $\mathrm{C} 57 \mathrm{BL} / 6)$ develop lethal acute infections, whereas mice with functional Nrampl (eg, Sv129S6) develop a chronic or sustained infection. Resistant mice often show no clinical disease, although Salmonella Typhimurium can persist for long periods within macrophages in the mesenteric lymph nodes. ${ }^{12-15}$ Interestingly, Salmonella Typhimurium has been detected in the CNS of both $\mathrm{Nrampl}^{+1+}$ and $\mathrm{Nrampl}^{-1-}$ strains of mice. ${ }^{8,9}$

To directly examine the influence of Nrampl on dissemination to the CNS and subsequent meningitis, we infected wild-type C57BL/6J (Nrampl ${ }^{-1-}$ ) and Nrampl-reconstituted C57BL/6 $\left(\mathrm{Nrampl}^{+/+}\right)$mice with Salmonella Typhimurium by oral gavage. $\mathrm{Nrampl}^{+/+} \mathrm{C} 57 \mathrm{BL} / 6$ are more resistant than wild-type C57BL/6 mice ${ }^{13}$ and provide a model to analyze how a stronger innate immune response may influence $\mathrm{Sal}$ monella infection of and damage to the brain. We examined the time course of Salmonella Typhimurium infection in the brain, the localization of bacteria within the CNS, and the neuroinflammatory response to infection. Almost all mice had detectable Salmonella in the CNS and developed mild foci of inflammation in the meninges, although the time course of infection and the histopathology differed between $\mathrm{Nrampl}^{-/-}$ and $\mathrm{Nrampl}^{+/+}$strains. In addition, a few $\mathrm{Nrampl}^{+/+}$mice developed a more severe CNS infection with clinical signs of neurological disease and histological features consistent with Salmonella-induced meningitis in humans, including ventriculitis and abscesses.

\section{Materials and Methods}

\section{Ethics Statement}

All animal work was performed in accordance with the Animal Welfare Act and Public Health Service Policy. Animal experiments were performed at the Rocky Mountain Laboratories (Hamilton, MT) or the University of Colorado at Boulder under protocols approved by the Institutional Animal Care and Use Committees (protocol numbers: RML 2014-028, RML 2014-070, UCB 1307.02).

\section{Mice}

C57BL/6J mice (Jackson Laboratories, Bar Harbor, ME), 129SvEvTac mice (Taconic Laboratories, Hudson, NY), and C57BL/6 Nramp $1^{\mathrm{G} 169 \mathrm{D}}$ mice homozygous for the wildtype Nrampl (Slc11al) allele derived from Sv129 mice ${ }^{16}$ (Dr. Ferric Fang and Dr. Steve Libby, University of Washington, Seattle) were used for these studies. Mice were kept in pathogen-free conditions with free access to food and water, except where noted.

\section{Bacterial Infections}

Salmonella enterica serovar Typhimurium wild-type strain SL1344 ${ }^{17}$ was grown to stationary phase for 18 hours at $37^{\circ} \mathrm{C}$ with shaking in Luria-Bertani-Miller broth supplemented with streptomycin $(100 \mu \mathrm{g} / \mathrm{mL})$. Bacteria were pelleted and diluted to the appropriate concentration based on the OD at $600 \mathrm{~nm}$. The actual inoculum size was verified by plating on Luria-Bertani plates for colony-forming units (CFUs). Adult 6- to 8-week-old 129SvEvTac (Taconic Laboratories), C57BL/6 Nrampl $1^{\mathrm{G} 169 \mathrm{D}}\left(\mathrm{Nrampl}^{-1-}\right)$, and C57BL/6 $\mathrm{Nrampl}^{\mathrm{Gly} 169}\left(\mathrm{Nrampl}^{+/+}\right)$mice were without food and water for 2 hours before oral inoculation (oral gavage) with Salmonella. The inoculum was administered in $100 \mu \mathrm{L}$ of sterile buffered pharmaceutical grade saline (Mediatech, Manassas, VA) using a 20-gauge gavage needle. Food and water were restored 1 hour after inoculation. Mice were monitored daily for signs of clinical illness (ie, ruffled fur, hunched posture, or ataxia). Under anesthesia, blood was collected via cardiac puncture before transcardial perfusion with $5 \mathrm{~mL}$ of heparin sterile buffered pharmaceutical grade saline $(100 \mathrm{U} / \mathrm{mL})$. Tissues (brain, spleen, and liver) were collected in preweighed tubes containing $500 \mu \mathrm{L}$ sterile buffered pharmaceutical grade saline, homogenized with a Precellys 24 homogenizer, and adjusted for concentration (based on weight) before plating and enumeration of CFUs. For most studies, the brain was divided into two sagittal sections, one half used for CFU counts and the other used for immunohistochemistry or flow cytometry.

\section{Flow Cytometry}

Brain tissue was homogenized using a 7-mL dounce homogenizer in $2 \mathrm{~mL}$ phosphate-buffered saline (PBS). Homogenate was strained using a $70 \mu \mathrm{mol} / \mathrm{L}$ cell strainer (Bioexpress, Kaysville, UT). The microglia fraction was collected at the $70 \% / 30 \%$ interface of a 70\%/30\%/0\% Percoll gradient after centrifugation. Cells were further processed for flow cytometry staining. $\mathrm{Fc}$ receptors were blocked using CD16/CD32 Fc $\gamma$ III/II (clone 2.4G2; BD Biosciences, San Jose, CA). Cells were stained using a combination of the following antibodies: CD11c-PE/Cy7 (clone HL3; BD Biosciences), F4/80-e450 (clone BM8; eBiosciences), CD45- PE (clone 30-F11; BD Biosciences), Ly6C-AF700 (clone AL-21; BD Biosciences), Ly6G-APC/Cy7 (clone 1A8; BD Biosciences,), CD4-APC/ Cy7 (clone GK1.5; BD Biosciences), CD8-PE (clone 53-6.7; BD Biosciences), NK1.1-AF700 (clone PK136; BD Biosciences), and CD45R/B220 (clone RA3-6B2; BD Biosciences), for 1 hour on ice, followed by a wash step and fixation in $2 \%$ paraformaldehyde for 20 minutes at room temperature. Cells were washed, resuspended in PBS, and processed for flow cytometry analysis. All flow analysis was done on a LSR II cytometer (BD Biosciences) and analyzed using FloJo software version 10.0.7 (FlowJo, Ashland, OR). 


\section{Histopathology}

Tissues were fixed in 10\% neutral buffered formalin (Leica Biosystems, Buffalo Grove, IL) for a minimum of 7 days before being placed in cassettes and processed with a Leica RM2265 microtome. Embedded tissues are divided into sections (5 $\mu \mathrm{m}$ thick) and dried overnight at $42^{\circ} \mathrm{C}$ before staining. Samples were deparaffinized and rehydrated using a graded series of xylene, ethanol $(100 \%, 95 \%, 70 \%)$, and PBS. Antigen retrieval was performed in a citrate buffer using a Decloaking Chamber (Biocare Medical, Concord, $\mathrm{CA})$ at $120^{\circ} \mathrm{C}$ for 20 minutes under high pressure. After PBS wash and blocking (2\% donkey serum, $1 \%$ bovine serum albumin, $0.1 \%$ Triton X-100, 0.05\% Tween-20 in PBS), the tissues were stained using rabbit anti-Ibal (1:200; Wako, Richmond, VA), rabbit anti-glial fibrillary acidic protein (1:500; Agilent, Santa Clara, CA), rabbit anti-CD3 (1:100; Dako), and goat anti-Salmonella common structural antigen (1:500; Kirkegaard \& Perry Laboratories, Inc., Gaithersberg, MD) primary antibodies. Secondary antibodies used were Alexa Fluor 488-conjugated chicken anti-rabbit and Alexa Fluor 594-conjugated chicken anti-goat (1:300; Life Technologies, Carlsbad, CA). Samples were mounted with ProLong Gold with DAPI (Life Technologies).

\section{Pathology Scoring}

All samples were scored blindly (D.S.) using the following criteria to assess for infiltration of inflammatory cells (ie, neutrophils) and presence of meningitis and/or encephalitis. Score 0 , no lesion; 1 , focal infiltration of the meninges and/or gray matter by small numbers of lymphocytes, macrophages, and rare neutrophils; 2, focal to multifocal foci in the meninges and gray matter or olfactory bulb that is infiltrated by small numbers of lymphocytes, macrophages, and few neutrophils, may be minimal hemorrhage; 3 , multifocal areas of encephalomalacia and meningitis with infiltration by moderate numbers of neutrophils, macrophages, and fewer lymphocytes, multifocal vasculitis with or without fibrin thrombi, multifocal mild hemorrhage, and numerous extracellular bacilli; and 4, coalescing areas of encephalomalacia and meningitis with infiltration by moderate numbers of neutrophils, macrophages, and fewer lymphocytes, multifocal vasculitis with or without fibrin thrombi, multifocal moderate hemorrhage, and numerous extracellular bacilli.

\section{Imaging}

Confocal images were captured using ZEN software version 8.1.10 (Carl Zeiss, Thornwood, NY) on a Carl Zeiss LSM710 confocal laser scanning microscope with either a Plan APOCHROMAT $63 \times / 1.4$ numerical aperture (NA) or a $20 \times / 0.8$ NA objective. Wide field images were acquired using Nikon Elements software ersion 3.2 on a Nikon Eclipse 55i microscope with either a $40 \times / 0.75$ NA or a $20 \times / 0.50$ NA objective and a Nikon DS-Ril digital camera (Nikon, Melville, NY). Slides were also imaged using ScanScope software version 102.0.0.33 (Leica) on either an Aperio ScanScope Fluorescent slide scanner or an Aperio XT Brightfield slide scanner, both equipped with a UPLSAPO $20 \times / 0.75$ NA objective (Leica). All image analysis was done with ImageJ (version 2.0.0 W.S. Rasband; NIH, Bethesda, MD) and Adobe Photoshop CS5.1 (Adobe, San Jose, CA).

\section{Statistical Analysis}

Graphpad software Statmate version 2.00 (GraphPad, La Jolla, CA) was used to determine group sizes before experimentation, and Graphpad Prism software version 7 was used for all statistical analyses. The tests are indicated in the figure legends.

\section{Results}

Detection of Salmonella in the Brain after Oral Infection in $\mathrm{Nramp}^{-/-}$and Nramp $1^{+/+}$Mice

Wild-type strains of Salmonella Typhimurium can disseminate to the brain and cause meningioencephalitis in susceptible mice, but it is not clear how this correlates with systemic infection and whether there is a dose-dependent response. ${ }^{8,9}$ To investigate these issues, we infected C57BL/6 $\left(\mathrm{Nrampl}^{-/-}\right)$ mice by oral gavage with doses ranging from $10^{4}$ to $10^{9}$ CFUs. Mice were monitored daily and euthanized when they developed clinical signs of salmonellosis (hunched posture and ruffled fur). No mice showed signs of neurological disease (ataxia, rolling, jumping, twirling, and loss of motor control). To avoid blood contamination of tissues, particularly the brain, transcardial perfusion was performed on all mice immediately before removing tissues. Bacterial loads were examined in the brain, blood, spleen, and liver by plating (Figure 1A). Irrespective of the inoculating dose, all mice $(n=10)$ with clinical bacteremia had high bacterial loads in the liver $\left(10^{6}\right.$ to $\left.10^{8} \mathrm{CFUs} / \mathrm{g}\right)$, spleen $\left(10^{7}\right.$ to $\left.10^{8} \mathrm{CFUs} / \mathrm{g}\right)$, and blood $\left(10^{4}\right.$ to $\left.10^{7} \mathrm{CFUs} / \mathrm{mL}\right)$. Bacteria $\left(10^{4}\right.$ to $\left.10^{6} \mathrm{CFUs} / \mathrm{g}\right)$ were also recovered from the brains of all of the symptomatic mice, although at lower levels than those found in the spleen or liver. Thus, bacteremia in C57BL/6 $\mathrm{Nrampl}^{-1-}$ mice correlated with infection of the CNS and did not show a dose dependence.

Although C57BL/6 mice are widely used as a model for systemic salmonellosis, their inability to control Salmonella Typhimurium during the early phase of infection means that they succumb to infection within 2 weeks (Figure 2). In contrast, Nrampl-reconstituted $\left(\mathrm{Nrampl}^{+/+}\right)$C57BL/6 mice control early infection, providing a useful model to study how the immune response may influence Salmonella infection of the CNS. To establish a baseline for the meningitis studies, we first compared the course of infection in Nrampl $^{-1-}$ and Nrampl $^{+/+}$C57BL/6 mice after oral gavage with $10^{8}$ or $10^{9} \mathrm{CFUs}$, respectively. These doses were selected based on initial experiments and on published studies so that $100 \%$ of the mice should develop systemic infection. ${ }^{13}$ Under these conditions, $<30 \%$ of rampl $^{+/+}$ mice developed clinical signs of disease by day 21 , whereas all of the $\mathrm{Nrampl}^{-1-}$ mice developed clinical signs of 

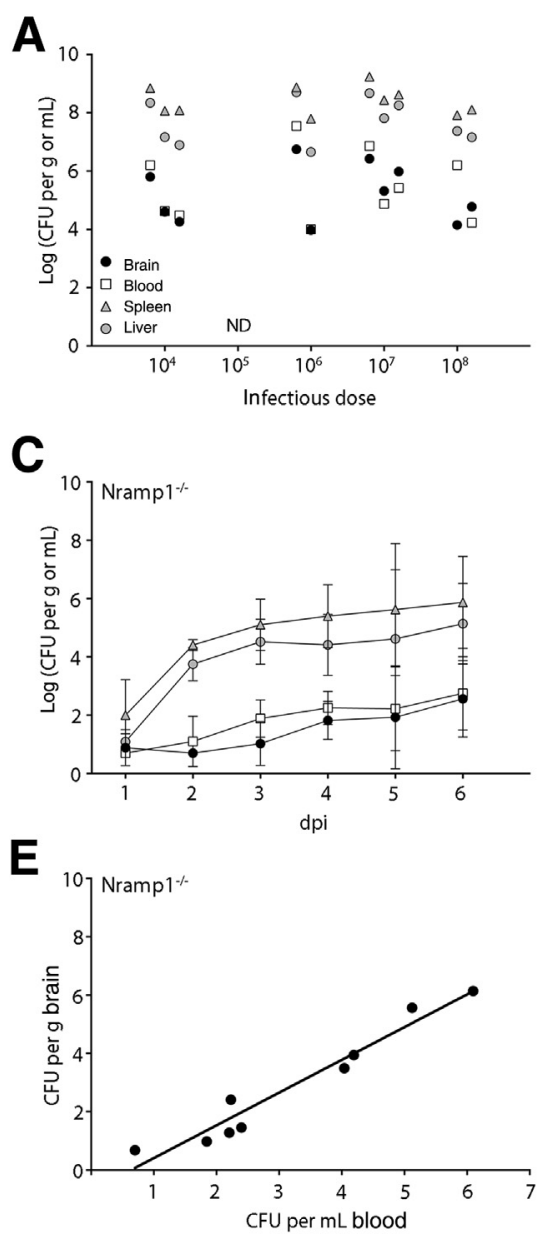

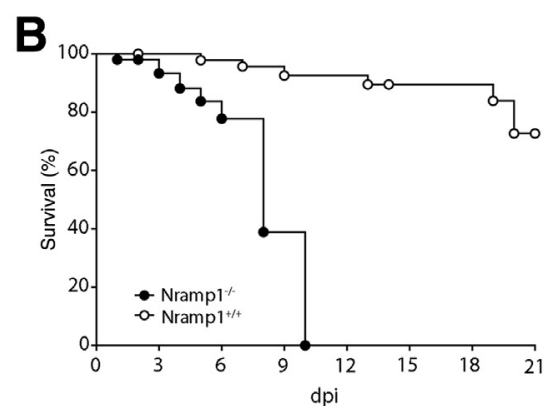

D

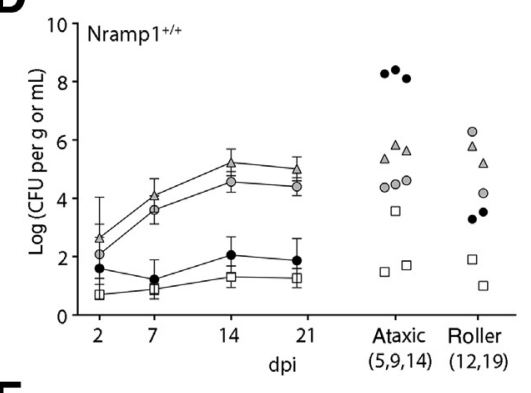

$\mathbf{F}$

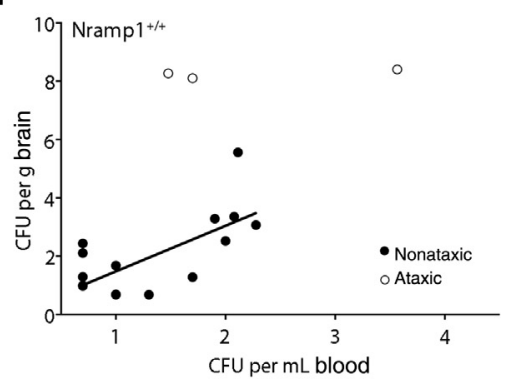

Figure 1 Salmonella infection and dissemination in Nramp $1^{-/-}$and $\mathrm{Nramp}^{+/+}$mice. A: Organ colonization of $\mathrm{Nramp1}^{-/-}$mice with clinical salmonellosis. Mice were infected orally with $10^{4}$, $10^{6}, 10^{7}$, or $10^{8}$ Salmonella. Samples were collected on development of clinical disease, up to 10 days postinfection (dpi). B: Percentage survival of $\mathrm{Nramp1}^{-/-}$and $\mathrm{Nramp1}^{+/+}$mice infected with $10^{8}$ or $10^{9}$ colony-forming units (CFUs) Salmonella, respectively. C: Bacterial loads in Nramp $1^{-1-}$ mice infected with $10^{8}$ Salmonella. D: Bacterial loads in Nramp $1^{+/+}$mice infected with $10^{9}$ Salmonella. Mice with clinical ataxia or rolling disease are shown separately. E and F: Relationship between bacterial loads in the blood and brain of $\mathrm{Nramp1}^{-/-}$(E) or $\mathrm{Nramp1}^{+/+}$(F) mice at 6 or 21 days postinfection. Data were fitted using a linear regression model of transformed log-log CFU data. Mice with ataxia are indicated. Data represent means \pm SD (C and D). $n=3\left(\mathbf{A}, 10^{4}\right.$ and $10^{7}$ Salmonella); $n=2\left(\mathbf{A}, 10^{6}\right.$ and $10^{8}$ Salmonella); $n=50\left(\mathbf{B}, \operatorname{Nramp}^{-/-}\right) ; n=54\left(\mathbf{B}, \operatorname{Nramp}^{+/+}\right)$; $n=3$ to 14 mice per time point (C); $n=2$ to 20 mice per time point (D). salmonellosis and were euthanized by day 10 (Figure 1B). The difference between these strains is consistent with previous findings ${ }^{13}$ and provides a model to study the effect of the peripheral immune response on Salmonella infection of the CNS.

To examine when Salmonella colonizes the CNS, and how Nrampl influences this process, we did a time course analysis of infection in $\mathrm{Nramp}^{+/+}$and $\mathrm{Nrampl}^{-1-}$ mice. Bacterial loads were determined daily, up to day 6 , in $\mathrm{Nrampl}^{-1-}$ mice and on days 2, 7, 14, and 21 in rrampl $^{+/+}$mice (Figure 1, C and D, and Supplemental Figures S1 and S2). Bacteria were recovered from the liver and spleen of most mice within 1 to 2 days of infection, although, as expected, the levels of bacteria did not peak until after 7 days in the Nrampl $^{+/+}$mice. Bacteria were recovered from the blood as early as 2 days postinfection (dpi) in $\mathrm{Nrampl}^{-1-}$ mice and 7 dpi in $\mathrm{Nrampl}^{+/+}$mice. Infection of the brain was slightly delayed compared to blood and peripheral tissues, with $>50 \%$ of mice having recoverable bacteria in the brain at $4 \mathrm{dpi}$ in Nrampl $^{-1-}$ mice (Supplemental Figure S1) and 14 dpi in Nrampl $^{+/+}$mice (Supplemental Figure S2). The bacterial load in the brain, which ranged from undetectable to $10^{6}$, was consistently lower than that in the spleen or liver for both $\mathrm{Nrampl}^{-1-}$ and Nrampl $^{+/+}$mice (Figure 1, C and D), with the exception of three Nrampl $^{+/+}$mice that had clinical signs of ataxia (Table 1). Thus, bacterial infection of the CNS was observed in most animals for both $\mathrm{Nrampl}^{-/-}$and $\mathrm{Nrampl}^{+/+}$mice after oral inoculation.

\section{Salmonella Colonization of the Brain Correlates with Bacteremia in Nramp $1^{-/-}$but Not Nramp1 ${ }^{+/+}$Mice}

The kinetics of bacterial loads in the brain followed the same trend as bacterial loads in the blood for both $\mathrm{Nrampl}^{-/-}$and Nrampl $^{+/+}$mice (Figure 1, C and D). Therefore, to investigate whether there was a direct correlation, we compared bacterial loads in the blood and brain for individual mice. A direct correlation was observed in $\mathrm{Nrampl}^{-1-}$ mice $\left(R^{2}=0.9450\right)$ (Figure $\left.1 \mathrm{E}\right)$; however, no correlation was observed in $\mathrm{Nrampl}^{+/+}$mice $\left(R^{2}=0.4744\right)$ (Figure $1 \mathrm{~F}$ ). This suggests that Salmonella levels in the blood may be more important for neuroinvasion in $\mathrm{Nrampl}^{-1-}$ mice, compared to Nrampl $^{+/+}$mice.

\section{Infection of the CNS in Mice Resistant to Salmonella Bacteremia}

Nrampl is only one of the genes that influences susceptibility to Salmonella infection in mice. ${ }^{13,18} 129$ S6 mice are 


\section{Nramp1+/+ (Sv129)}

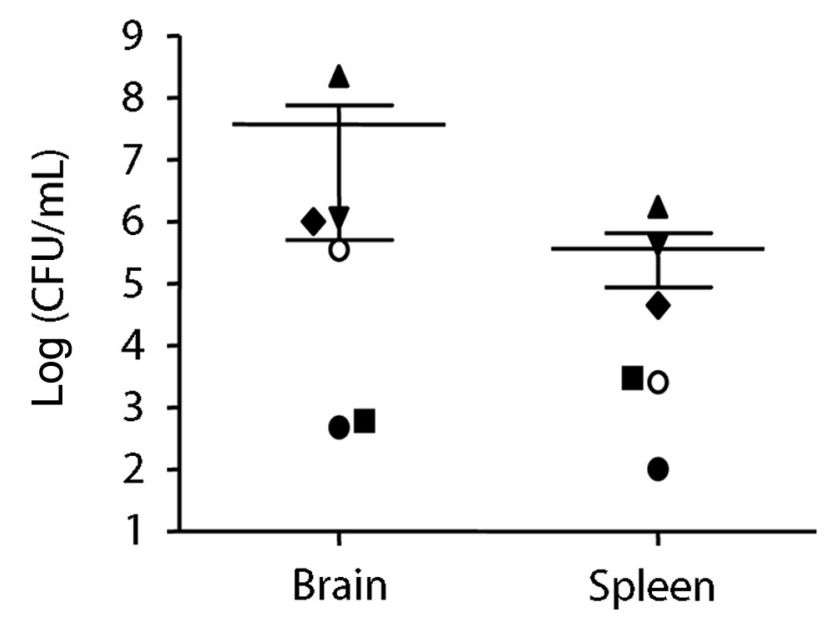

Figure 2 Salmonella colonization of the brain of $129 \mathrm{~S} 6$ (129SvEv) mice. Mice were orally infected with $10^{9}$ Salmonella. Samples were collected 2 weeks after infection. Each symbol represents one mouse. Means and SEM are shown. $n=6$. CFU, colony-forming unit.

more resistant to Salmonella infection than the reconstituted Nrampl $^{+/+}$C57BL/6 mice. ${ }^{13}$ To determine whether other genetic factors may also influence Salmonella infection in the brain, we examined 129S6 mice. However, even in the more resistant 129S6 mice, Salmonella could be readily detected in the brain (Figure 2), suggesting that even restriction factors that prevent bacteremia were not sufficient to prevent Salmonella from entering the CNS.

\section{Salmonella Infection Results in Inflammatory Monocyte Recruitment to the Brain}

A characteristic feature of bacterial meningitis, in humans and animal models, is the recruitment of inflammatory cells, including monocytes, macrophages, and neutrophils. ${ }^{19,20}$ To assess which inflammatory cells are recruited during Salmonella infection, we isolated cells from the brain by

Table 1 Comparison of Clinical Signs and Histopathology

\begin{tabular}{|c|c|c|c|c|}
\hline \multirow[b]{2}{*}{ Variable } & \multicolumn{2}{|c|}{ Clinical diagnosis* } & \multicolumn{2}{|c|}{$\begin{array}{l}\text { Histopathology } \\
\text { positive }^{\dagger}\end{array}$} \\
\hline & Nramp1 $^{-/-}$ & Nramp1 $1^{+/+}$ & Nramp1 ${ }^{-/-}$ & Nramp $1^{+/+}$ \\
\hline Total analyzed & 27 & 20 & 1 & 10 \\
\hline Asymptomatic & 19 & 9 & 1 & 3 \\
\hline Salmonellosis & 8 & 6 & 0 & 3 \\
\hline Roller & 0 & 2 & 0 & 1 \\
\hline Ataxic & 0 & 3 & 0 & 3 \\
\hline
\end{tabular}

*Mice analyzed include animals at earlier time points (Figure 1C) that had not progressed to clinical disease but were analyzed for histological changes.

${ }^{\dagger}$ Number of animals from Clinical Diagnosis columns that scored positive for clear signs of meningitis or encephalitis by blinded histological examination (D.S.) of hematoxylin and eosin sections.
Percoll gradient and analyzed them for different cell markers by flow cytometry. We selected 4 and 6 dpi for Nrampl $^{-1-}$ mice and 7 and 14 dpi for $\mathrm{Nrampl}^{+/+}$mice based on the bacterial loads in the brain at those time points (Figure 1). For each mouse, half of the brain was used for flow cytometry, whereas the other half was used to determine the bacterial load. Infiltrating cells were separated from resident microglia and other brain cells by $\mathrm{CD} 45^{\mathrm{hi}}$ expression (Figure 3A). Cells were then defined as dendritic cells $\left(\mathrm{CD} 11 \mathrm{c}^{+}\right)$, T cells $\left(\mathrm{CD} 3^{+}\right)$, B cells $\left(\mathrm{CD} 45 \mathrm{R} / \mathrm{B} 220^{+}\right)$, natural killer cells $\left(\mathrm{NK} 1.1^{+}\right)$, or myeloid cells $\left(\mathrm{CD} 11 \mathrm{~b}^{+}\right)$. Myeloid cells were further characterized as neutrophils $\left(\mathrm{Ly}_{6 \mathrm{G}}{ }^{+}\right)$, inflammatory M1 monocytes $\left(\mathrm{Ly} 6 \mathrm{C}^{\mathrm{hi}}\right.$ and Ly6G ${ }^{-}$), or nonclassic M2 monocytes (Ly6 $\mathrm{C}^{\mathrm{lo}}$ and $\mathrm{Ly}_{6 \mathrm{G}}{ }^{-}$) (Figure 3A).

Infiltrating $\left(\mathrm{CD} 45^{\mathrm{hi}}\right)$ cells were observed in both strains, relative to mock-infected controls (Figure 3B). Mice with detectable CFUs in the CNS generally had a higher percentage of infiltrating cells relative to infected mice without detectable CFUs (Figure 3B). In both strains, the infiltrating cells were composed primarily of M1 and M2 monocytes with lower levels of neutrophils, dendritic cells, T cells, B cells, and natural killer cells (Figure 3B and Supplemental Figure S3). Thus, Salmonella infection resulted in recruitment of inflammatory cells to the brain, primarily M1 and M2 monocytes, in both $\mathrm{Nrampl}^{+/+}$and $\mathrm{Nrampl}^{-/-}$mice. Interestingly, the presence of NRAMP1, which inhibits the ability of Salmonella to replicate in monocytes, did not appear to substantially affect the cell types in the CNS. Similar to monocyte infiltrate in the brain, we also found increased M1 and M2 monocytes in the blood of both $\mathrm{Nrampl}^{+/+}$and $\mathrm{Nrampl}^{-/-}$mice (Supplemental Figure S4). Neutrophils were also increased in $\mathrm{Nrampl}^{+/+}$ mice, whereas an increase in natural killer cells was observed in $\mathrm{Nrampl}^{-/-}$mice. The increase in both monocyte populations in the blood correlates with the detection of these cell types in the brain and indicates a proliferation of monocytes from the bone marrow in response to Salmonella infection in both $\mathrm{Nrampl}^{+/+}$and $\mathrm{Nrampl}^{-/-}$mice.

\section{Histological Analysis Demonstrates More Severe Meningitis and Encephalitis in Nramp1 ${ }^{+/+}$Mice Compared to Nramp1 ${ }^{-/-}$Mice}

In both $\mathrm{Nrampl}^{-1-}$ and $\mathrm{Nrampl}^{+/+}$mice, we observed consistent bacterial infection and inflammatory cell recruitment to the brain after Salmonella infection (Figures 1 and 3), which are indicative of meningitis or encephalitis. Next, hematoxylin and eosin-stained sections of brain tissue were analyzed in a blinded manner (D.S.) by a pathologist using a scoring system of 0 to 4 to rank meningitis and encephalitis (Tables 1 and 2). Only 1 of 27 (approximately 4\%) $\mathrm{Nrampl}^{-1-}$ mice scored positive for meningitis, whereas 10 of $20(50 \%) \mathrm{Nrampl}^{+/+}$mice scored positive for meningitis and/or encephalitis. Of the mice that scored positive by histology, four were 
A
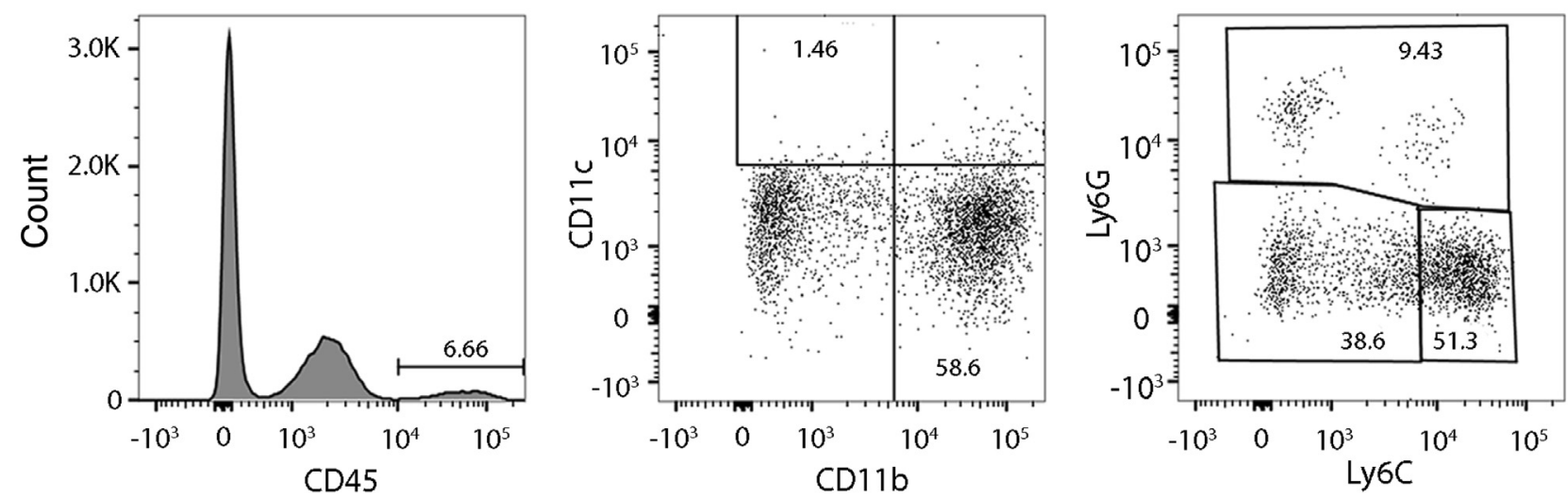

B

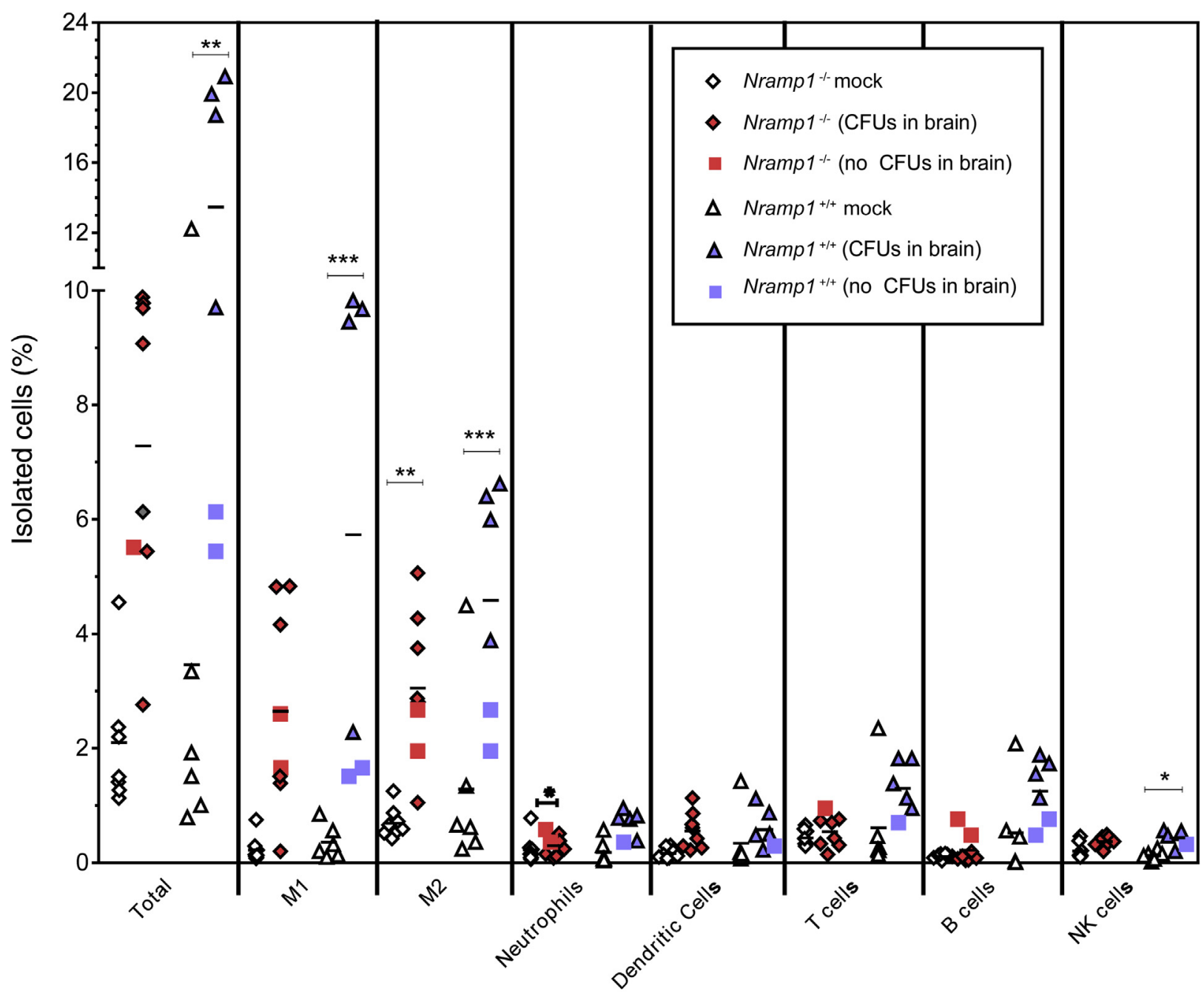

Figure 3 Infiltration of immune cells in the brains of infected $\mathrm{Nramp}^{-/-}$and $\mathrm{Nramp1}^{+/+}$mice. Mice were orally infected with Salmonella, and samples were collected on day $6\left(\mathrm{Nramp1}^{-/-}\right)$and day $14\left(\mathrm{Nramp}^{+/+}\right)$after infection. A: Example of gated analysis used for determining M1 and M2 cell phenotypes. B: Percentage of infiltrating immune cells in the brains of infected $\mathrm{Nramp1}^{-1-}$ (red symbols) and Nramp1 ${ }^{+/+}$(blue symbols) mice. Half of the brain was used to estimate the bacterial load [colony-forming units (CFUs)], whereas the other half was processed for flow cytometry. Infected mice, where no CFUs were detected, are indicated for Nramp1 ${ }^{-/-}$(red squares) and Nramp1 ${ }^{+/+}$(blue squares). Mock-infected Nramp1 ${ }^{-/-}$(white diamonds) and Nramp1 ${ }^{+/+}$(white triangles) mice were used as controls. Each symbol represents one mouse. $n=8$ (B, infected and mock-infected Nramp1 ${ }^{-1-}$ mice); $n=6$ (B, infected and mock-infected Nramp $1^{+/+}$mice). ${ }^{*} P<0.05,{ }^{* *} P<0.01$, and ${ }^{* * *} P<0.001$. NK, natural killer. 
Table 2 Individual Pathology Scores of Mice

\begin{tabular}{|c|c|c|c|c|c|}
\hline Mouse no. & Nramp1 & Clinical diagnosis & $\mathrm{CFU} / \mathrm{g}$ & Meningitis* & Encephalitis $^{\dagger}$ \\
\hline $51-2$ & $-1-$ & Asymptomatic & $2.00 \times 10^{4}$ & 1 & 2 \\
\hline $92-4$ & $+/+$ & Asymptomatic & $1.40 \times 10^{4}$ & 1 & 0 \\
\hline $126-2$ & $+/+$ & Asymptomatic & $4.60 \times 10^{3}$ & 2 & 0 \\
\hline $92-3$ & $+/+$ & Salmonellosis & $8.80 \times 10^{4}$ & 1 & 0 \\
\hline $135-2$ & $+/+$ & Salmonellosis & $3.60 \times 10^{5}$ & 0 & 2 \\
\hline $93-3$ & $+/+$ & Ataxic & $1.90 \times 10^{8}$ & 4 & 4 \\
\hline $126-1$ & $+/+$ & Ataxic & $2.50 \times 10^{8}$ & 2 & 4 \\
\hline $135-1$ & $+/+$ & Ataxic & $1.30 \times 10^{8}$ & 4 & 4 \\
\hline
\end{tabular}

*Tissue was scored for meningitis based on a ranking of 0 to 4, as described in Materials and Methods.

TTissue was scored for encephalitis based on a ranking of 0 to 4, as described in Materials and Methods.

CFU, colony-forming unit; + , positive; - , negative.

asymptomatic, three had salmonellosis, one showed signs of rolling, and three had signs of ataxia (Table 2); all had detectable CFUs in the brain. Thus, meningitis and encephalitis were observed in a greater percentage of Nrampl $^{+/+}$mice compared to Nrampl $^{-1-}$ mice and were observed in both asymptomatic and symptomatic mice. The three Nramp $^{+/+}$mice with ataxia had the highest bacterial load in their brains $\left(10^{8} \mathrm{CFUs} / \mathrm{g}\right)$ as well as the highest scores for meningitis $(4,2,4)$ and encephalitis $(4,4,4)$.
Immunohistochemistry Analysis Shows Focal Areas of Inflammation in the Meninges and Ventricles of Both Nramp1 $^{-/-}$and Nramp1 ${ }^{+/+}$Mice

To determine the localization of Salmonella and inflammation in the brain of infected mice, we used immunohistochemistry. Tissue sections were stained with anti-Iba1 to detect microglia and monocytes, anti-glial fibrillary acidic protein to detect astrocytes, anti-CD31 to detect

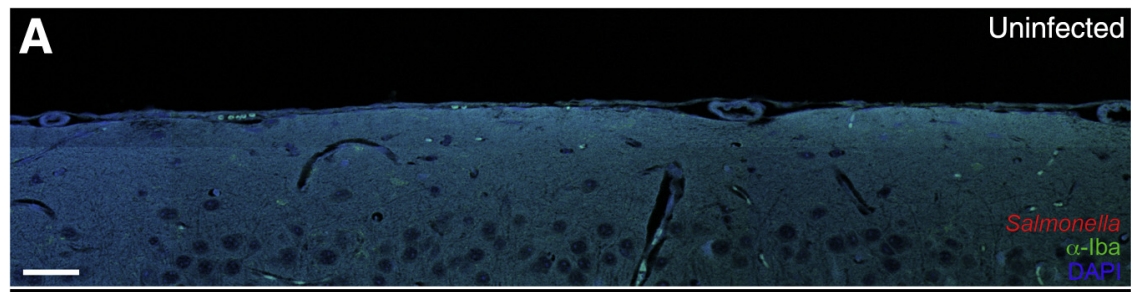

$\mathbf{B}$
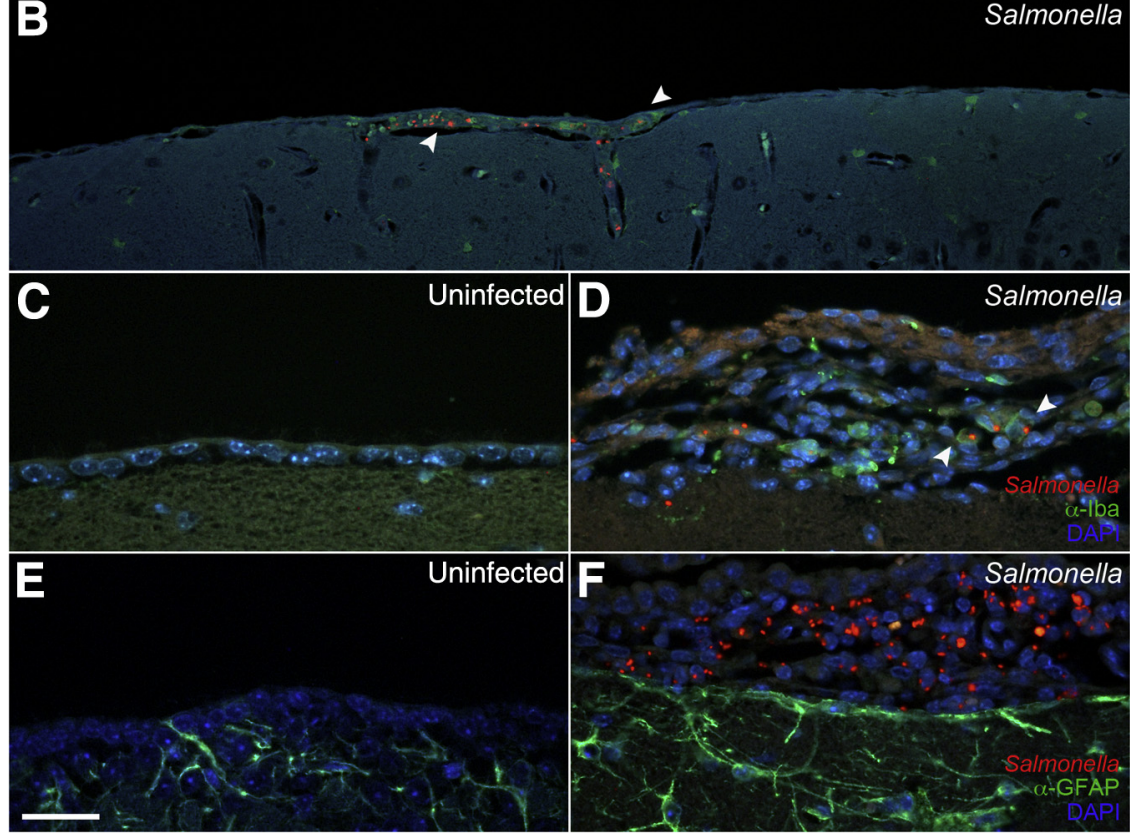

Figure 4 Meningitis in Nramp1 ${ }^{-/-}$mice after Salmonella infection. Brain tissue of $\mathrm{Nramp1}^{-/-}$ mice orally infected with Salmonella was fixed and immunostained up to 10 days after infection. A and B: Extended representative images of uninfected (A) and infected (B) brain tissue immunostained for Iba1 (green), Salmonella (red), and DAPI (blue). Arrowheads indicate regions of meningitis. C-F: High-magnification representative images of uninfected ( $\mathbf{C}$ and $\mathbf{E}$ ) and infected (D and $\mathbf{F}$ ) brain tissue immunostained for Salmonella (red), DAPI (blue), and either glial fibrillary acidic protein (GFAP) or Iba1 (green). Scale bars $=40 \mu \mathrm{m}(\mathbf{A}-\mathbf{F})$. 

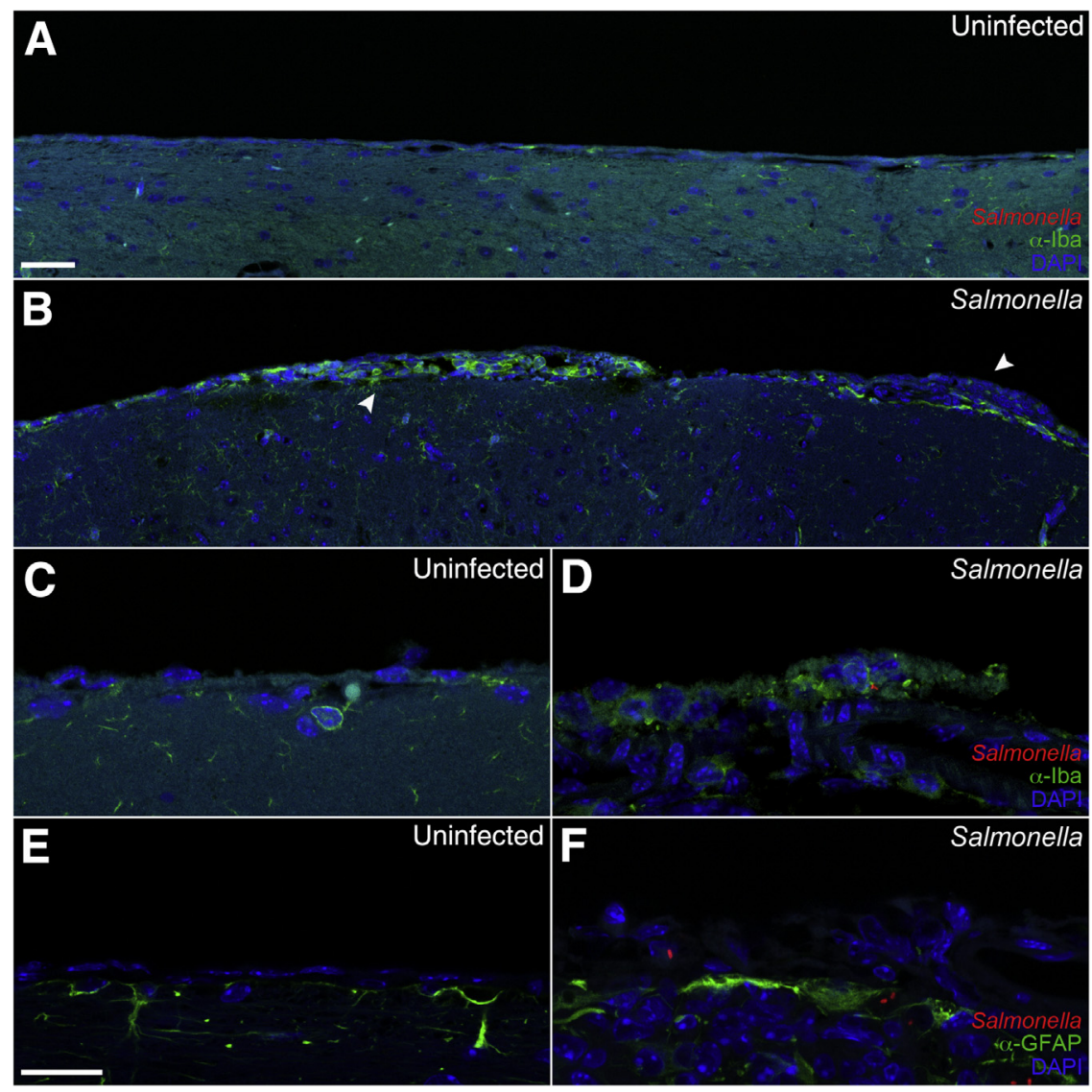

Figure 5 Meningitis in $\mathrm{Nramp1}^{+/+}$mice after Salmonella infection. Brain tissue of $\mathrm{Nramp}^{+/+}$ mice orally infected with Salmonella was fixed and immunostained up to 21 days after infection. A and $\mathbf{B}$ : Extended representative images of uninfected (A) and infected (B) brain tissue immunostained for Iba1 (green), Salmonella (red), and DAPI (blue). Arrowheads indicate regions of meningitis. C-F: High-magnification representative images of uninfected ( $\mathbf{C}$ and $\mathbf{E}$ ) and infected (D and $\mathbf{F}$ ) brain tissue immunostained for Salmonella (red), DAPI (blue), and either glial fibrillary acidic protein (GFAP) or Iba1 (green). Scale bars: $40 \mu \mathrm{m}(\mathbf{A}$ and $\mathbf{B}) ; 20 \mu \mathrm{m}(\mathbf{C}-\mathbf{F})$. endothelial cells, and anti-lipopolysaccharide to detect Salmonella. Focal areas of inflammation consisting of $\mathrm{Iba1}^{+}$monocytes/macrophages (green fluorescence) and Salmonella were observed in the meninges and ventricles in most mice with detectable CFUs in the brain (Figures 4 and 5). These mice included animals that were scored negative for meningitis and encephalitis, possibly because of the focal nature of the areas of inflammation. Interestingly, Salmonella in these focal areas was generally more intense in $\mathrm{Nrampl}^{-1-}$ mice (Figure 4) than in $\mathrm{Nrampl}^{+/+}$ mice (Figure 5). These focal areas of infection were associated with increased glial fibrillary acidic protein staining at the meningeal layer (Figures 4 and 5), indicating astrocyte activation in response to infection. Salmonella was often found within $\mathrm{Iba}^{+}$monocytes in the meningeal layer (Figure 4, Figure 6, A and B, and Figure 7), but extracellular bacteria were occasionally found within the brain parenchyma (Figure 6C and Figure 7) in both $\mathrm{Nrampl}^{-/-}$and $\mathrm{Nrampl}^{+/+}$mice. Focal areas of meningitis and ventriculitis were observed in both strains of mice, consisting of Salmonella, Salmonellainfected monocytes, and other inflammatory cells. These immunohistochemistry studies correlated with the detection of Salmonella CFUs in the brain of both Nramp1 $1^{-1-}$ and $\mathrm{Nrampl}^{+/+}$mice (Figure 1), as well as the increase in monocytes (Figure 3).
Pathology Correlates with Neurological Signs of Ataxia in $\mathrm{Nramp1}^{+/+}$Mice

Of the $53 \mathrm{Nrampl}^{+/+}$mice infected with Salmonella, 5 (10\%) developed clinical signs of disease clearly distinguishable from systemic salmonellosis (hunched posture and ruffled fur). These fell into two distinct groups. Two mice displayed barrel rolling and spinning behaviors, whereas three displayed classic signs of ataxia, including hind limb tremors, failure to splay legs, grasping of paws, and altered gait. Comparison of the bacterial burdens of these two groups (Figure 1D) revealed that the ataxic mice had much higher bacterial loads in the brain $\left(>10^{8} \mathrm{CFUs} / \mathrm{g}\right)$, whereas the roller mice had loads similar to asymptomatic mice $\left(10^{3}\right.$ CFUs/g). Remarkably, although the bacterial burden in the brains of ataxic mice was 1000 - to 10,000 -fold higher than all other mice, the bacterial levels in other organs remained comparable (Figure 1D). Thus, the three Nrampl $^{+/+}$animals that developed signs of neurological disease were associated with high bacterial levels in the brain.

Imaging of brain tissue from the three ataxic animals revealed multiple areas of necrotizing vasculitis often occluded by fibrin thrombi (Figure 8). Brains from these three mice contained periventricular malacia associated with infiltration of large numbers of intact and degenerate neutrophils, 

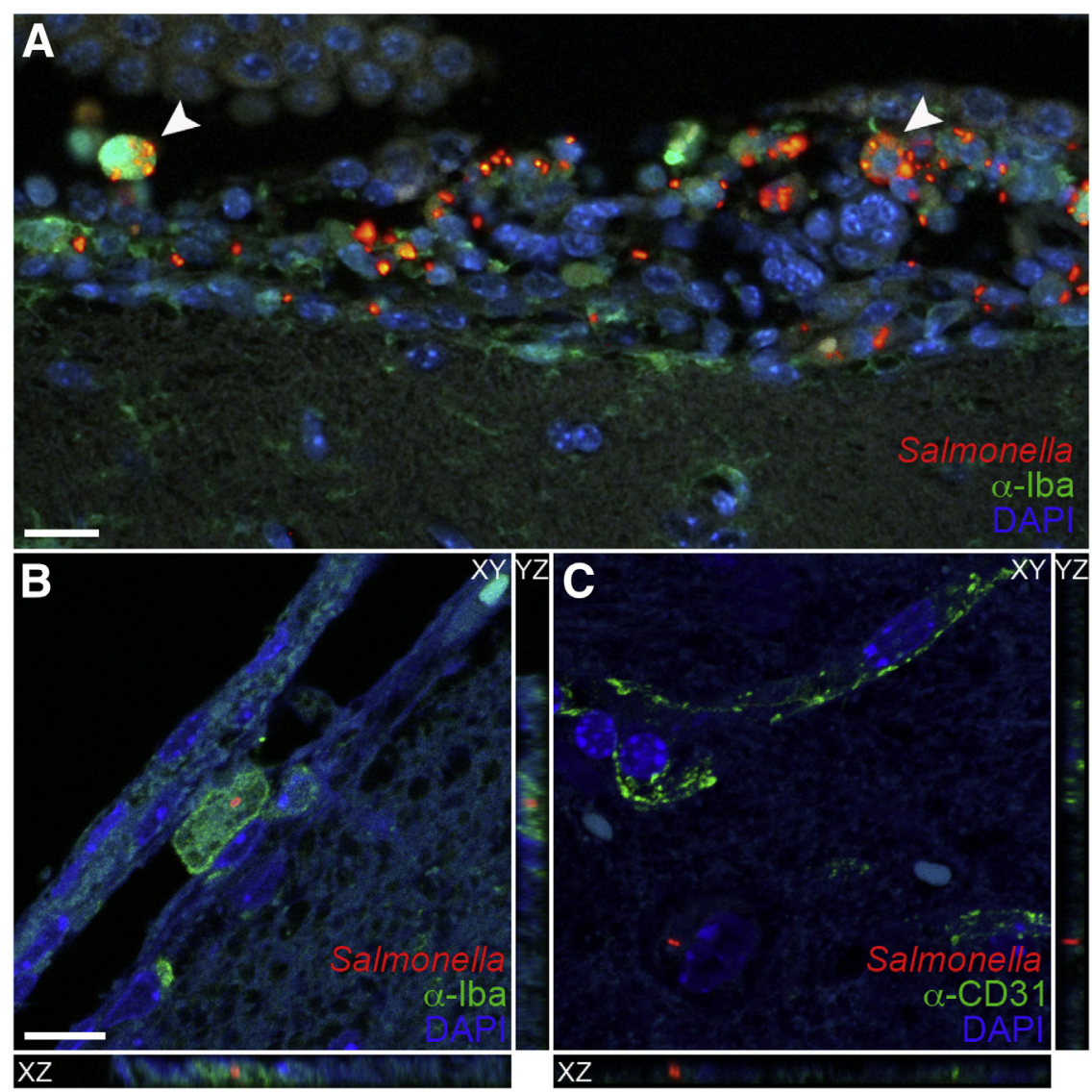

which were not observed in uninfected controls (Figure 8). Similar signs of inflammation were observed in the lateral and third ventricles (Figure 8). Thus, ataxic mice had histological changes characteristic of Gram-negative bacillary meningoencephalitis. ${ }^{21}$ Fluorescence immunohistochemistry and confocal microscopy revealed that the severe histological changes in the ataxic Nrampl $^{+/+}$mice were associated with areas of bacterial infection. Salmonella was observed in the olfactory bulb (Figure 9A), periventricular areas (Figure 9B), ventricles (Figure 9, C and D), and meninges (Figure 9, E and F). Most Salmonella was found in the areas of periventricular malacia and neutrophil infiltration (Figure 9, B-D), but was not directly observed around blood vessels associated with necrotizing vasculitis (areas of red blood cell infiltration as shown by white cells) (Figure 9B). Thus, Salmonella infection was widespread in ataxic mice, although primarily localized to the ventricles, periventricular areas, and meninges.

Immunohistochemistry of brain tissue sections from the two roller mice did not show significant bacteria (Supplemental Figure S5A), consistent with the lack of severe neurological pathology (Table 1) and the low CFU
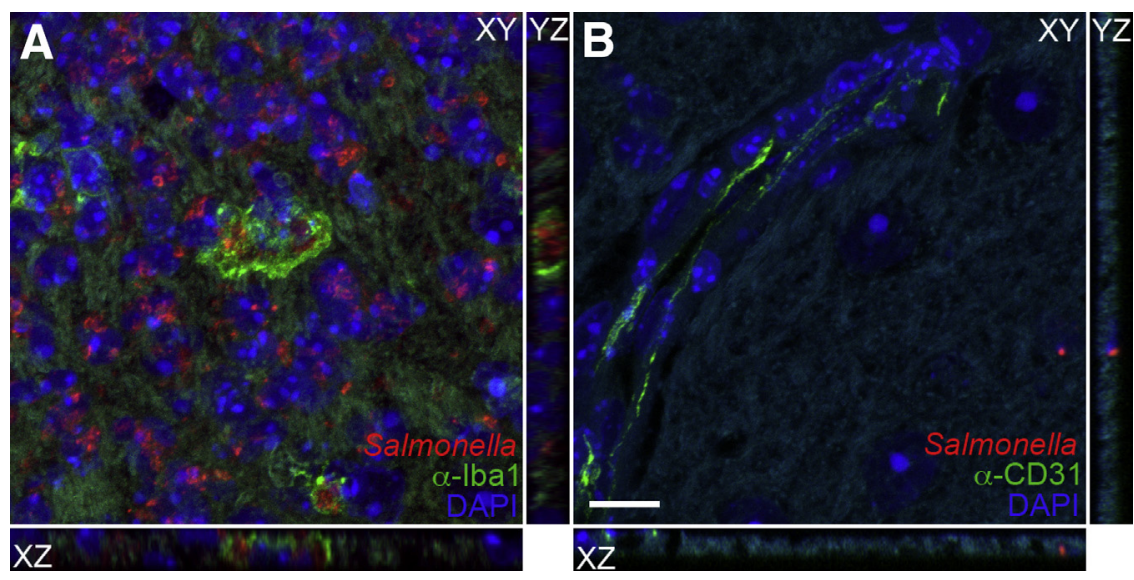

Figure 7 Salmonella infection of the brain parenchyma in $\mathrm{Nramp1}^{+/+}$neurological mice. Brain tissue of $\mathrm{Nramp1}^{+/+}$mice orally infected with Salmonella was fixed and immunostained at 5 , 9, and 14 days after infection. XYZ projections illustrating presence of intracellular and extravascular bacteria in the parenchyma immunostained for Salmonella (red), DAPI (blue), and either Iba1 (green; A) or CD31 (green; B). XZ and YZ images were acquired in the $X Y$ plane with slices taken along the Z-axis. Scale bar $=10 \mu \mathrm{m}(\mathbf{A}$ and $\mathbf{B})$. 

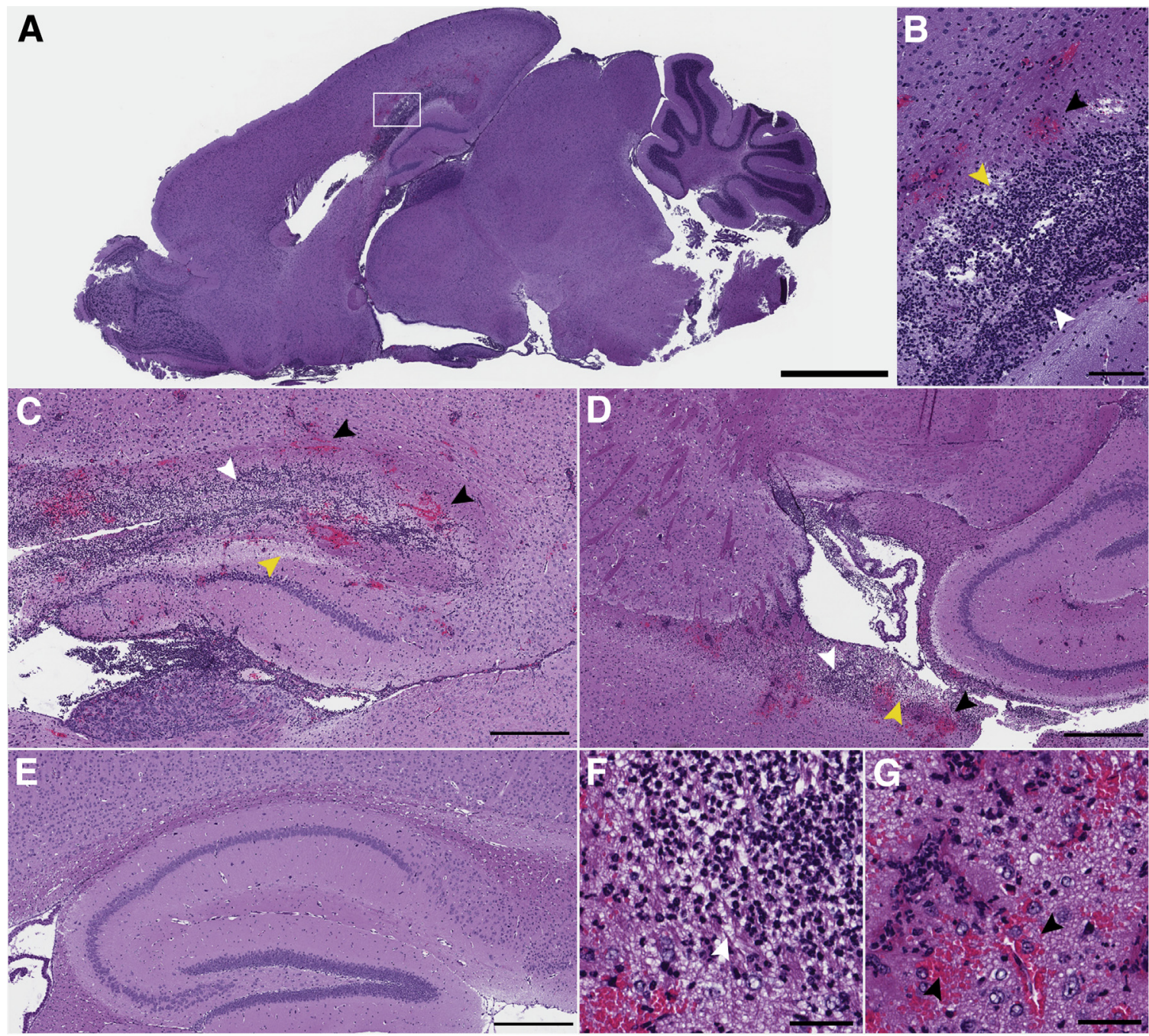

Figure 8 Neutrophil infiltration, focal hemorrhaging, and ventriculitis in the brains of ataxic Nramp $1^{+/+}$mice. Brains from mice with clinical signs of ataxia after infection with Salmonella were stained with hematoxylin and eosin. A: Low-magnification image showing neutrophil infiltration and hemorrhaging (boxed area), magnified in B. Malacia with neutrophil infiltrate and focal hemorrhaging in the corpus callosum (B and C) and lateral ventricle (D). E: Image of hippocampus and corpus callosum from an uninfected mouse for comparison. $\mathbf{F}$ and $\mathbf{G}$ : Infiltration and vascular thrombosis. Black arrowheads indicate regions of hemorrhage; yellow arrowheads, regions of tissue clearing; and white arrowheads, regions of cellular infiltrate. Scale bars: $2 \mathrm{~mm}(\mathbf{A}) ; 200 \mu \mathrm{m}(\mathbf{B}) ; 500 \mu \mathrm{m}$ $(\mathbf{C}-\mathbf{E}) ; 50 \mu \mathrm{m}$ (F and $\mathbf{G})$.

counts (Figure 1D). Because signs of spinning and barrel rolling can be indicative of otitis media (ear infection), we analyzed one of the roller mice for Salmonella infection in the inner ear. Bacterial infection was readily detected in the ear, as determined by fluorescent labeling for Salmonella (Supplemental Figure S5, B, C, and E). Histological examination revealed monocytes in the ear canal (Supplemental Figure S5, D and F), as confirmed by immunohistochemistry staining for Iba1 (Supplemental Figure S5E). Thus, the clinical sign of barrel rolling was associated with an acute inner ear infection, rather than CNS infection.

\section{Discussion}

Gram-negative meningitis is a serious health concern, with high mortality and long-term sequelae. However, there are only a few animal models that reconstitute the natural route of infection of the CNS, making it difficult to fully understand the progression of the disease. In the current study, we compared the development of meningitis in highly susceptible $\mathrm{Nrampl}^{-/-}$and more resistant $\mathrm{Nrampl}^{+/+}$mice following a natural route of Salmonella infection. In both strains, meningitis was observed with detectable levels of Salmonella in the CNS and an influx of monocytes and other immune cells in the brain. In addition, a small number of Nrampl ${ }^{+/+}$animals developed clinical neurological disease characterized by ataxia. The pathology observed in these mice was similar to that reported in human neurological disease cases of Salmonella meningitis, including ventriculitis and hemorrhage. ${ }^{6,22}$ Thus, oral infection of Salmonella results in meningitis in both susceptible and resistant strains of mice, with a more severe form of meningitis occurring infrequently in resistant mice. The 

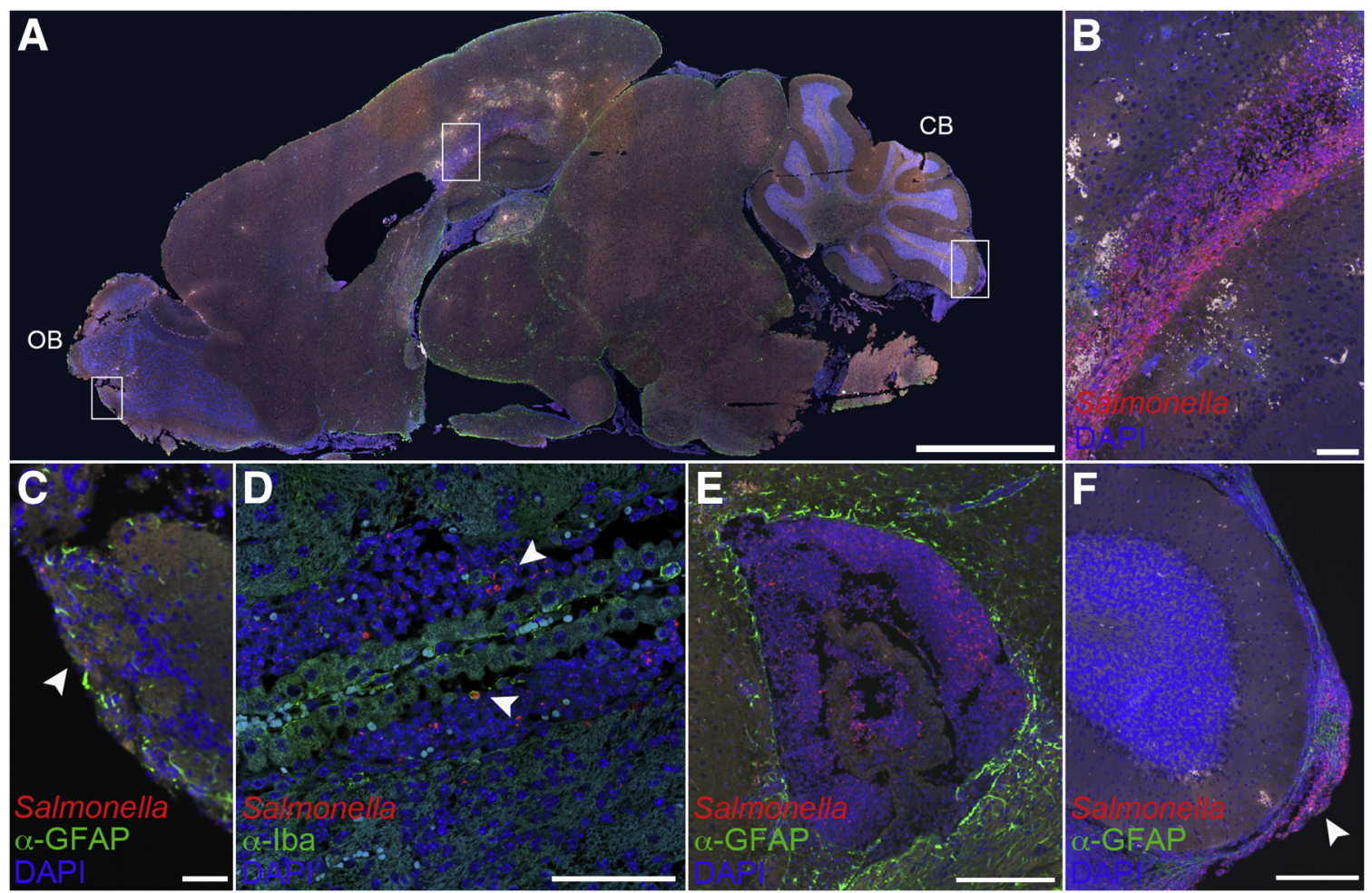

Figure 9 Bacterial accumulation and macrophage infiltration in the brains of ataxic Nramp1 ${ }^{+/+}$mice. Brains from mice with clinical signs of ataxia after infection with Salmonella were immunostained. A: Low-magnification image of infected brain tissue immunostained for glial fibrillary acidic protein (GFAP; green), Salmonella (red), and DAPI (blue). Boxed regions illustrate bacteria in the corpus collosum, olfactory bulb, and meningies and are magnified in B, C, and $\mathbf{F}$, respectively. For orientation purposes, the olfactory bulb $(\mathrm{OB})$ and cerebellum $(\mathrm{CB})$ are labeled. Representative image of Salmonella in the corpus callosum (B), olfactory bulb (C), ventricle (D and E), and cerebellar meninges (F) of a neurological mouse immunostained for either Iba1 or GFAP (green), Salmonella (red), and DAPI (blue). Arrowheads represent intracellular bacteria present in a monocyte (D) and presence of bacterial meningitis (F). Scale bars: $2 \mathrm{~mm}(\mathbf{A}) ; 100 \mu \mathrm{m}(\mathbf{B}-\mathbf{D}) ; 200 \mu \mathrm{m}$ (E and $\mathbf{F})$.

development of the more severe form of meningitis could be linked to the persistent infection in $\mathrm{Nrampl}^{+/+}$mice, which may allow more opportunity for Salmonella to cross the blood-brain or blood-cerebrospinal fluid (CSF) barriers and gain better access to the CSF. Once Salmonella infects the CSF, it may be able to evade the immune system and replicate to high enough levels to then induce the severe damage observed in the brains in the ataxic Nramp1 $1^{+/+}$ mice. Future studies on how Salmonella gains access to the CSF and whether the CSF environment allows for uncontrolled replication of Salmonella remain important to answer questions that need to be addressed.

Both Salmonella and Escherichia coli K1, the most common cause of neonatal Gram-negative bacillary meningitis in the United States, are enteropathogens that enter the CNS through hematogenous spread. The mechanism of bacterial entry into the CNS is not well understood. Experimental models for Gram-negative meningitis are limited. In most cases, adult animals do not reliably develop meningitis unless the pathogen is inoculated directly into the CSF or by intracranial installation. Although these models have yielded important information about the factors leading to, and the effects of, meningeal inflammation, they bypass the natural dissemination of the bacteria from the vascular system to the central nervous system.
An important aspect of the current study was the ability to follow bacterial dissemination from the gastrointestinal tract via the blood into the CNS. Our studies suggest that macrophages may play an important role in this process for Salmonella. One of the primary host factors that restrict intracellular survival of Salmonella in macrophages is Nrampl. We found that bacteremia levels correlated strongly with brain CFUs in $\mathrm{Nrampl}^{-1-}$ mice, but not in $\mathrm{Nrampl}^{+/+}$ mice. Salmonella-infected monocytes were also readily detected in the brains of $\mathrm{Nrampl}^{-1-}$ mice, consistent with the inability of $\mathrm{Nrampl}^{-/-}$monocytes to effectively suppress Salmonella growth. ${ }^{16,23}$ These Salmonella-infected monocytes were not as readily detected in the brains of $\mathrm{Nrampl}^{+/+}$ mice, despite higher numbers of cells in the CNS. Thus, $\mathrm{Nrampl}^{-1-}$ and $\mathrm{Nrampl}^{+/+}$mice provide two distinct models of Salmonella meningitis, with strong differences in the ability of monocytes to control the Salmonella infection. Comparison of these two models will provide a better understanding of how monocytes mediate meningitis in immunocompetent and immunocompromised hosts.

Studies in humans and animal models for $E$. coli $\mathrm{K} 1$ have indicated that a high degree of bacteremia is a prerequisite for invasion of the CNS, ${ }^{24,25}$ with at least $10^{5} \mathrm{CFUs} / \mathrm{mL}$ required in adult animals. ${ }^{26}$ However, herein, brain neuroinvasion of Salmonella was observed when the blood levels 
were at least $2 \operatorname{logs}$ lower, approximately $10^{3} \mathrm{CFUs} / \mathrm{mL}$ in Nrampl $^{-1-}$ mice and $<10^{2} \mathrm{CFUs} / \mathrm{mL}$ in $\mathrm{Nrampl}^{+/+}$mice. Thus, in this model, Salmonella may have a lower bacteremia threshold for entry into the CNS. Whether or not this lower requirement is because of a role for monocyte/ macrophage trafficking of bacteria into the CNS remains to

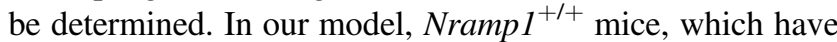
lower bacteremia levels, had greater infiltration of monocytes in the brain than rrampl $^{-1-}$ mice. Thus, there was no direct correlation between monocytes in the CNS and bacteremia with Salmonella infection. However, it is unclear if there is a percentage of monocytes infected with Salmonella that differs between $\mathrm{Nrampl}^{+/+}$and $\mathrm{Nrampl}^{-1-}$ mice, which could influence the contribution of infected monoctyes to Salmonella infection in the brain.

Multiple myeloid cell types have been shown to contribute to inflammation and pathogenesis in the brain, including resident microglia, M1 inflammatory monocytes, M2 nonclassic monocytes, and resident brain macrophages. In this model, both M1 and M2 infiltrating monocytes were increased in both strains of mice, even in animals with almost undetectable bacteria in the brain. M1 and M2 monocyte populations may have distinct functions in meningitis, as M1 monocytes are considered to be more proinflammatory, whereas M2 monocytes are considered to be anti-inflammatory, as evidenced by their production of anti-inflammatory cytokines, such as IL-10. ${ }^{27}$ In E. coli K1 studies, depletion of circulating M1 monocytes resulted in more severe meningitis, but this was because of peripheral control of bacteremia rather than a direct effect within the $\mathrm{CNS}^{28}$ As $\mathrm{Nrampl}^{-1-}$ monocytes have limited ability to clear bacterial infections, the role of these cells in Salmonella meningitis may be mostly damaging. In contrast, Nrampl $^{+/+}$monocytes may have both protective and pathogenic roles in the disease process.

In conclusion, we found that oral inoculation of Salmonella, the natural route of infection, results in meningitis in both resistant and susceptible strains of mice. This meningitis includes the presence of Salmonella in the CNS as well as the recruitment of inflammatory cells to the brain. This provides a unique opportunity to dissect out these processes and gain a better understanding of the underlying mechanisms of disease progression that leads to Gramnegative bacterial meningitis.

\section{Acknowledgments}

We thank Suzette A. Priola, Byron Caughey, and Brent Race for critical reading of the manuscript; and Dan Long, Nancy Kurtz, and Aaron B. Carmody for technical assistance with experiments.

\section{Supplemental Data}

Supplemental material for this article can be found at http://dx.doi.org/10.1016/j.ajpath.2016.09.002.

\section{References}

1. Ramakrishnan M, Ulland AJ, Steinhardt LC, Moïsi JC, Were F, Levine OS: Sequelae due to bacterial meningitis among African children: a systematic literature review. BMC Med 2009, 7:47

2. Feasey NA, Dougan G, Kingsley RA, Heyderman RS, Gordon MA: Invasive non-typhoidal salmonella disease: an emerging and neglected tropical disease in Africa. Lancet 2012, 379:2489-2499

3. Swann O, Everett DB, Furyk JS, Harrison EM, Msukwa MT, Heyderman RS, Molyneux EM: Bacterial meningitis in Malawian infants less than 2 months of age: etiology and susceptibility to World Health Organization first-line antibiotics. Pediatr Infect Dis J 2014, 33 : $560-565$

4. Wu HM, Huang WY, Lee ML, Yang AD, Chaou KP, Hsieh LY: Clinical features, acute complications, and outcome of Salmonella meningitis in children under one year of age in Taiwan. BMC Infect Dis 2011, 11:30

5. Bryan JP, Scheld WM: Therapy of experimental meningitis due to Salmonella-enteritidis. Antimicrob Agents Chemother 1992, 36: 949-954

6. Lee WS, Puthucheary SD, Omar A: Salmonella meningitis and its complications in infants. J Paediatr Child Health 1999, 35:379-382

7. Oliveira CR, Morriss MC, Mistrot JG, Cantey JB, Doern CD, Sánchez PJ: Brain magnetic resonance imaging of infants with bacterial meningitis. J Pediatr 2014, 165:134-139

8. Bollen WS, Gunn BM, Mo H, Lay MK, Curtiss R III: Presence of wild-type and attenuated Salmonella enterica strains in brain tissues following inoculation of mice by different routes. Infect Immun 2008, $76: 3268-3272$

9. Wickham ME, Brown NF, Provias J, Finlay BB, Coombes BK: Oral infection of mice with Salmonella enterica serovar Typhimurium causes meningitis and infection of the brain. BMC Infect Dis 2007, 7: $65-71$

10. Wessling-Resnick M: Nramp1 and other transporters involved in metal withholding during infection. J Biol Chem 2015, 290:18984-18990

11. Vidal S, Tremblay ML, Govoni G, Gauthier S, Sebastiani G, Malo D, Skamene E, Olivier M, Jothy S, Gros P: The Ity/Lsh/Bcg locus: natural resistance to infection with intracellular parasites is abrogated by disruption of the Nramp1 gene. J Exp Med 1995, 182:655-666

12. Monack DM, Mueller A, Falkow S: Persistent bacterial infections: the interface of the pathogen and the host immune system. Nat Rev Microbiol 2004, 2:747-765

13. Brown DE, Libby SJ, Moreland SM, McCoy MW, Brabb T, Stepanek A, Fang FC, Detweiler CS: Salmonella enterica causes more severe inflammatory disease in C57/BL6 Nramp1 ${ }^{\mathrm{G} 169}$ mice than Sv129S6 mice. Vet Pathol 2013, 50:867-876

14. Brown DE, McCoy MW, Pilonieta MC, Nix RN, Detweiler CS: Chronic murine typhoid fever is a natural model of secondary hemophagocytic lymphohistiocytosis. PLoS One 2010, 5:e9441

15. Tsolis RM, Xavier MN, Santos RL, Bäumler AJ: How to become a top model: impact of animal experimentation on human Salmonella disease research. Infect Immun 2011, 79:1806-1814

16. Govoni G, Vidal S, Gauthier S, Skamene E, Malo D, Gros P: The $\mathrm{Bcg} / \mathrm{Ity} / \mathrm{Lsh}$ locus: genetic transfer of resistance to infections in C57BL/6J mice transgenic for the Nramp1 Gly169 allele. Infect Immun 1996, 64:2923-2929

17. Hoiseth SK, Stocker BA: Aromatic-dependent Salmonella typhimurium are non-virulent and effective as live vaccines. Nature 1981, 291: 238-239

18. Loomis WP, Johnson ML, Brasfield A, Blanc MP, Yi J, Miller SI, Cookson BT, Hajjar AM: Temporal and anatomical host resistance to chronic Salmonella infection is quantitatively dictated by Nramp1 and influenced by host genetic background. PLoS One 2014, 9:e111763

19. Diab A, Abdalla H, Li HL, Shi FD, Zhu J, Höjberg B, Lindquist L, Wretlind B, Bakhiet M, Link H: Neutralization of macrophage inflammatory protein 2 (MIP-2) and MIP- $1 \alpha$ attenuates neutrophil 
recruitment in the central nervous system during experimental bacterial meningitis. Infect Immun 1999, 67:2590-2601

20. Mildner A, Djukic M, Garbe D, Wellmer A, Kuziel WA, Mack M, Nau R, Prinz M: $\mathrm{Ly}_{-} 6 \mathrm{G}^{+} \mathrm{CCR} 2^{-}$myeloid cells rather than Ly- $6 \mathrm{C}^{\text {high }} \mathrm{CCR} 2^{+}$monocytes are required for the control of bacterial infection in the central nervous system. J Immunol 2008, 181: 2713-2722

21. Bentlin MR, Ferreira GL, Rugolo L: Neonatal meningitis according to the microbiological diagnosis: a decade of experience in a tertiary center. Arq Neuropsiquiatr 2010, 68:882-887

22. Johan AJ, Hung LC, Norlijah O: Salmonella enteritidis ventriculitis. Southeast Asian J Trop Med Public Health 2013, 44: 456-459

23. Fritsche G, Nairz M, Libby SJ, Fang FC, Weiss G: Slc11a1 (Nramp1) impairs growth of Salmonella enterica serovar typhimurium in macrophages via stimulation of lipocalin-2 expression. J Leukoc Biol 2012, 92:353-359

24. Dietzman DE, Fischer GW, Schoenknecht FD: Neonatal Escherichia coli septicemia-bacterial counts in blood. J Pediatr 1974, 85:128-130

25. Kim KS: Escherichia coli translocation at the blood-brain barrier. Infect Immun 2001, 69:5217-5222

26. Xie Y, Kim KJ, Kim KS: Current concepts on Escherichia coli K1 translocation of the blood-brain barrier. FEMS Immunol Med Microbiol 2004, 42:271-279

27. Italiani P, Boraschi D: From monocytes to M1/M2 macrophages: phenotypical vs. functional differentiation. Front Immunol 2014, 5:514

28. Ribes S, Regen T, Meister T, Tauber SC, Schütze S, Mildner A, Mack M, Hanisch UK, Nau R: Resistance of the brain to Escherichia coli K1 infection depends on MyD88 signaling and the contribution of neutrophils and monocytes. Infect Immun 2013, 81:1810-1819 